\title{
Synergistic Use of Remote Sensing and Modeling for Tracing Dust Storms in the Mediterranean
}

\author{
D. G. Kaskaoutis, ${ }^{1}$ A. K. Prasad, ${ }^{2,3}$ P. G. Kosmopoulos, ${ }^{4}$ P. R. Sinha, ${ }^{5}$ S. K. Kharol, ${ }^{6,7}$ \\ P. Gupta, ${ }^{8,9}$ H. M. El-Askary, ${ }^{2,3,10}$ and M. Kafatos ${ }^{2,3}$ \\ ${ }^{1}$ Research and Technology Development Centre, Sharda University, Knowledge Park III, Greater Noida, 201-306, India \\ ${ }^{2}$ Center for Excellence in Earth Observing, Schmid College of Science and Technology, Chapman University, Orange, CA 92866, USA \\ ${ }^{3}$ School of Earth and Environmental Sciences, Schmid College of Science and Technology, Chapman University, Orange, \\ CA 92866, USA \\ ${ }^{4}$ Laboratory of Meteorology, Department of Physics, Athens University, Athens, Greece \\ ${ }^{5}$ National Balloon Facility, Tata Institute of Fundamental Research, Hyderabad 500 062, India \\ ${ }^{6}$ Atmospheric Science Section, Oceanography Division, National Remote Sensing Centre, Department of Space-Government of India, \\ Hyderabad 500 625, India \\ ${ }^{7}$ Department of Physics and Atmospheric Science, Dalhousie University, Halifax, NS, Canada \\ ${ }^{8}$ Universities Space Research Association, Greenbelt, MD 20770, USA \\ ${ }^{9}$ NASA Goddard Space Flight Center, Greenbelt, MD 20770, USA \\ ${ }^{10}$ Department of Environmental Sciences, Faculty of Science, Alexandria University, Moharem Bek, Alexandria 21522, Egypt
}

Correspondence should be addressed to D. G. Kaskaoutis, dimitriskask@hotmail.com

Received 17 November 2011; Accepted 17 January 2012

Academic Editor: Achuthan Jayaraman

Copyright (C) 2012 D. G. Kaskaoutis et al. This is an open access article distributed under the Creative Commons Attribution License, which permits unrestricted use, distribution, and reproduction in any medium, provided the original work is properly cited.

\begin{abstract}
This study focuses on the detection of the dust source region and monitoring of the transport of the dust plume from its primary outflow to final deposition. The application area is the Sahara desert and the eastern Mediterranean, where two dust events occurred during the period 4-6 February 2009, an unusual event for a winter period. The Aqua-MODIS and OMI observations clearly define the spatial distribution of the dust plumes, while the CALIPSO observations of total attenuated backscatter (TAB) at $532 \mathrm{~nm}$, depolarization ratio (DR), and attenuated color ratio (1064/532 nm) on 5 February 2009 provide a clear view and vertical structure of the dust-laden layer. The dust source region is defined to be near the Chad-Niger-Libyan borders, using satellite observations and model (DREAM) output. This dust plume is vertically extended up to $2.5 \mathrm{~km}$ and is observed as a mass plume of dust from surface level to that altitude, where the vertical variation of TAB (0.002 to 0.2) and DR (0.2-0.5) implies dust-laden layer with non-spherical particles. CALIPSO profiles show that after the dust plume reached at its highest level, the dust particles start to be deposited over the Mediterranean and the initial dust plume was strongly attenuated, while features of dust were limited below about $1-1.5 \mathrm{~km}$ for latitudes northern of $\sim 36^{\circ}$ (Greek territory).
\end{abstract}

\section{Introduction}

Desert areas are the main sources of aerosols, with the mineral dust comprising more than 35\% (1500-2600 $\left.\mathrm{Tgyr}^{-1}\right)$ of the primarily emitted aerosol mass [1]. Elevated dust plumes favor tropospheric heating and modify the temperature profile, while interactions with black carbon aerosols and pollutants alter their physical and chemical properties, such as size distribution, chemical composition, morphology, and hygroscopicity (e.g., [2-10]). Desert dust plays an important role in radiative forcing, with an estimated global mean Top of Atmosphere (TOA) radiative forcing in the range of -0.6 to $0.4 \mathrm{Wm}^{-2}$ [1]. However, the radiative forcing caused by dust particles is very uncertain in both magnitude and sign $[11,12]$, mainly triggered by the chemical composition of mineral particles [13], the wavelength dependence of the dust optical properties [12], the albedo of the underlying surface [14], and also the relative height between the dust 
layer and the clouds [15]. Desert dust can be transported over long distances from the source regions, with the larger particles be deposited near the source, while the smaller ones are suspended in the air for a few days or weeks, thus travelling over large distances [16].

The Sahara desert is the most important dust source region in the world [17-20]. The occurrence of Saharan dust (SD) events above eastern Mediterranean has a marked seasonal cycle, with a spring maximum and a winter minimum [8, 21-23]. In the summer, dust identification over the region is also frequent due to the longer duration of the dust particles favored by the stable weather conditions, the absence of depressions, and precipitation that favor their wet deposition. Many studies [24, 25] have shown that the Saharan dust events over Mediterranean are mainly driven by the intense cyclones called Sharav, south of the Atlas Mountains (Morocco), mainly during spring and summer. However, depending on the season, various mechanisms for dust outflow and transport are observed under diverse meteorological patterns, plume characteristics, and source regions $[24,25]$.

Due to the large spatial distribution and the heterogeneous aerosol field over areas affected by dust plumes, the existing ground-based measurements are not capable of monitoring the whole dust cycle, and a combination of ground-based and satellite observations is usually required [26-29]. The MODIS aerosol data (dark target algorithm) have demonstrated their utility for dust monitoring at regional and global scales [30,31], but they cannot be readily used to identify the dust sources because of difficulties associated with the large albedo over arid surface. The use of TOMS and OMI aerosol Index (AI) presents some promising results for the identification of the dust source regions although its coarse spatial resolution compared to MODIS [32] presents challenges, while the MODIS new algorithm Deep Blue is capable for aerosol retrievals over land [33]. Finally, CALIPSO profiles, although very useful for the identification of the dust vertical distribution (e.g., [9, $34,35]$ ), have a very small swath for the overall monitoring of the dust source regions and transport pathways. Therefore, the synergistic use of passive and active remote sensing, along with models (like DREAM) describing the whole dust cycle, provides a new era not only for monitoring the spatial and vertical extend of dust, but also for identifying its source regions.

In the present study, a combination of passive and active satellite retrievals is performed for monitoring the dust cycle in the eastern Mediterranean atmosphere, from its initial outbreak over Sahara to its final dilution and deposition over the Mediterranean Sea and Greece. More specifically, CALIPSO, MODIS, and OMI retrievals are utilized for the detection of the dust source region, the vertical extent of the dust plume, its spatial coverage, and the temporal variability for dust events occurring during the winter period of February 2009. Although the spatial and vertical distribution of dust, as well as its impacts over the Mediterranean has been systematically studied over the years, the main contribution of the present work is the identification of the dust storm region via combined CALIPSO, MODIS, and OMI observations, as well as to provide useful information about their interrelationship in AOD retrievals using the Deep Blue algorithm over land. The satellite observations are also qualitatively compared with model (DREAM) simulations.

\section{Dataset}

2.1. MODIS Retrievals. The two MODIS sensors have widely been used for the identification of the dust in several locations over the globe $[12,26,29,33,36]$. MODIS has been acquiring daily global data in 36 spectral bands from visible to thermal infrared $(29$ spectral bands with $1 \mathrm{~km}$ resolution, 5 spectral bands with $500 \mathrm{~m}$ resolution, and 2 with $250 \mathrm{~m}$ resolution, nadir pixel dimensions) for retrievals of aerosol properties over land and ocean. The data used in this study include Aqua-MODIS aerosol products, that is, $\mathrm{AOD}_{550}$ and Angstrom exponent at 550-865 nm over ocean from Dark Target algorithm [37] as well as $\mathrm{AOD}_{550}$ over land from the Deep Blue algorithm [33]. Collection 5 (C005, updated to new version 5.1) Aqua-MODIS retrievals were used over the study region (eastern Mediterranean) during the period 4-6 February 2009 with a spatial resolution of $10 \times 10 \mathrm{~km}$ (Level 2) derived from the MODIS level-2 data.

2.2. CALIPSO Retrievals. The Cloud-Aerosol Lidar and Infrared Pathfinder Satellite Observation (CALIPSO) provides new insight in monitoring of atmospheric dust $[9,38-$ 40] by observing the vertical profiles of aerosols and clouds. As part of the NASA A-Train constellation that includes the Aqua, CloudSat, Aura, and PARASOL satellites, CALIPSO has a $98^{\circ}$-inclination orbit and flies at an altitude of $705 \mathrm{~km}$ providing daily global maps of the vertical distribution of aerosols and clouds since spring 2006. The CALIPSO payload consists of three instruments: the Cloud-Aerosol Lidar with Orthogonal Polarization (CALIOP), an Imaging Infrared Radiometer (IIR), and a moderate spatial resolution Wide Field-of-view Camera (WFC). CALIOP provides profiles of backscatter coefficient at 532 and $1064 \mathrm{~nm}$, as well as two orthogonal (parallel and perpendicular) polarization components at $532 \mathrm{~nm}$. The CALIOP can observe aerosol over bright surfaces and beneath thin clouds as well as in clear sky conditions. In the present work we used Level 1B data that contain a half orbit (day or night) of calibrated and geolocated single-shot (highest resolution) lidar profiles, including attenuated backscatter at $532 \mathrm{~nm}$, depolarization ratio (DR) at $532 \mathrm{~nm}$, and attenuated color ratio (ACR) of band $532 \mathrm{~nm}$ and $1064 \mathrm{~nm}$. The vertical resolution of the retrievals is $30 \mathrm{~m}$. Retrieving the spatial and optical properties of aerosols and clouds from the CALIPSO backscatter data is confronted by several difficulties that are not faced in the analysis of ground-based lidars. Among these is the very large distance from the target, the high speed at which the satellite traverses the ground track, and the low signalto-noise ratios that result from the restrictions imposed on space-based platforms. The CALIPSO calibration and uncertainty as well as the CALIOP data products have been documented elsewhere [41]. 
2.3. OMI Retrievals. The Aerosol Index (AI) obtained via the Aura-OMI Level-2G (OMTO3, Version 003) with a spatial resolution of $0.25^{\circ} \times 0.25^{\circ}$ was used over the study region during the dusty days. AI is a qualitative indicator of nearUV absorbing aerosol particles such as smoke or mineral dust and does not provide indication of sulfate aerosols. The AI is defined as the difference between the measured (including aerosol effects) spectral contrast at the 331 and $360 \mathrm{~nm}$ wavelength radiances and the contrast calculated from the radiative transfer theory for a pure molecular (Rayleigh particles) atmosphere [42]. The UV absorbing aerosols (such as smoke and desert dust) produce smaller contrast than predicted by the pure Rayleigh scattering, and they yield positive values, against the near zero or negative ones for the clouds and nonabsorbing aerosols. The AI is especially suitable for detecting the presence of elevated absorbing aerosols above high reflecting surfaces, such as desert and snow/ice, and can also be detected intermingled with clouds and above cloud decks [43]. This concerns great importance regarding the identification of the dust source regions [32] and in cases when dust plumes are intermingled with clouds. However, the sensitivity of AI to dust aerosols depends strongly on aerosol layer height, while any aerosol below $\sim 1000 \mathrm{~m}$ is unlikely to be detected [44]. Recently OMI instrument has gone through row anomalies; therefore, quantitative use of the data has been avoided in the current study.

2.4. DREAM Model Simulations. The integrated modeling system Dust Regional Atmospheric Modeling (DREAM) (http://www.bsc.es/projects/earthscience/DREAM/) [45] has been widely used for the 3-D simulation of the dust cycle. The model takes into account the major processes of the dust cycle in the atmosphere, from its uplift and advection to wet and dry deposition. The near-surface wind, thermal conditions, and soil features are used for the simulation of the dust production based on the soil moisture, shear-free convection, and turbulent mixing. Furthermore, high-spatial resolution databases including elevation, soil properties, and vegetation cover are included in the model. The model uses 4 categories for dust-particle size, clay, small silt, large silt, and sand with typical radii of $0.73,6.1,18$, and $38 \mu \mathrm{m}$, respectively. The atmospheric lifetime for the first two size bins is larger than $\sim 12 \mathrm{~h}$, and these particles can be transported to long distances whereas the latter 2 are deposited near dust source region. Through continuing development and validation, DREAM has now reached to a high level of dust forecasting able to predict almost all the major dust events over Mediterranean (e.g., $[46,47])$.

\section{Results}

3.1. Dust Events and Meteorology. The Terra-MODIS true color RGB images, obtained from MODIS surface reflectance product MOD09 (http://modis.gsfc.nasa.gov/data/dataprod/ dataproducts.php?MOD_NUMBER=09), during the studied period are shown in Figure 1 covering eastern Mediterranean and surroundings. On the dusty days (4 and 6 February) extensive cloudiness occurred over Greece and the Balkan countries, while the main part of the eastern Mediterranean and Africa was cloudless allowing the dust plumes to be observable. More specifically, on 4 February the dust plume covers the Libyan and Aegean Seas with larger intensity at southern latitudes exhibiting a sharp northwards direction. On the next day some hints of remaining dust are observed over the Bay of Sirti, while the Greek territory is rather clean and cloudless with mean ground measured $\mathrm{PM}_{10}$ mass concentration values of $20 \mu \mathrm{gm}^{-3}$ in Athens and AERONET$\mathrm{AOD}_{500}$ of 0.083 over Crete. However, on 6 February, a new intense dust outbreak started from Algeria desert is joined with another one from Libya and transported towards Greece following a north/northeasterly direction. On that day, the eastern Aegean Sea is free from dust, but is strongly influenced on the next day (not shown). On both days the main dust plumes seem to be transported below the clouds. This is verified from CALIPSO observations showing transport of dust well below $2.5 \mathrm{~km}$, while the cloud base was well above $3-3.5 \mathrm{~km}$. According to the weather report of the National Observatory of Athens, the visibility was limited to a few hundred meters on 4 and 6-7 February in Athens, while 5 February was a day with relative clean sky and good visibility. At midday of 6 February a slight precipitation $(0.7 \mathrm{~mm})$ took place over Athens, however, not being able to dilute the dusty atmosphere, which was remained turbid until the evening hours of 7 February when an intense rainfall $(29 \mathrm{~mm})$ took place scavenging the dust particles.

The seasonally changed synoptic meteorological conditions over Mediterranean and surrounding continents are the force dynamics for the different air masses affecting the region as well as the outflow, transport pathways, and vertical extent of dust $[8,48,49]$. The meteorological pattern responsible for the present dust outflows is mainly associated with a trough over the Iberian peninsula and a surface cyclone centered over Italy and Adriatic Sea. The result of this atmospheric circulation is a northward flow associated with strong surface and mid-troposphere winds carrying significant amount of dust from Libya over eastern Mediterranean and Greece. It is worth to be noted that the dust outflow on 4 February 2009 covers the same area with those which occurred on 21 February 2001 [24] and 17 April 2005 [31], indicating similarity in the dust source regions and transport mechanisms. Such meteorological fields favoring dust exposure are more frequent in late winter (although rare) and early spring, since this period favors the depressions above Mediterranean. The duration of such dust events is 1-2 days, since the depressions favoring them are quickly moved and attenuated. They are usually associated with extensive cloud cover over the eastern Mediterranean and Greece, while the dust plume is mainly transported below the clouds (Figure 1). The wind field on the dusty days is shown along with the DREAM dust simulations (Figures 4 and 5).

3.2. Spatial Distribution of Dust Plumes from MODIS and OMI. The spatial distribution of the $\mathrm{AOD}_{550}$ (a) and Angstrom exponent $\left(\alpha_{550-865}\right)$ over ocean $(b)$, as obtained 

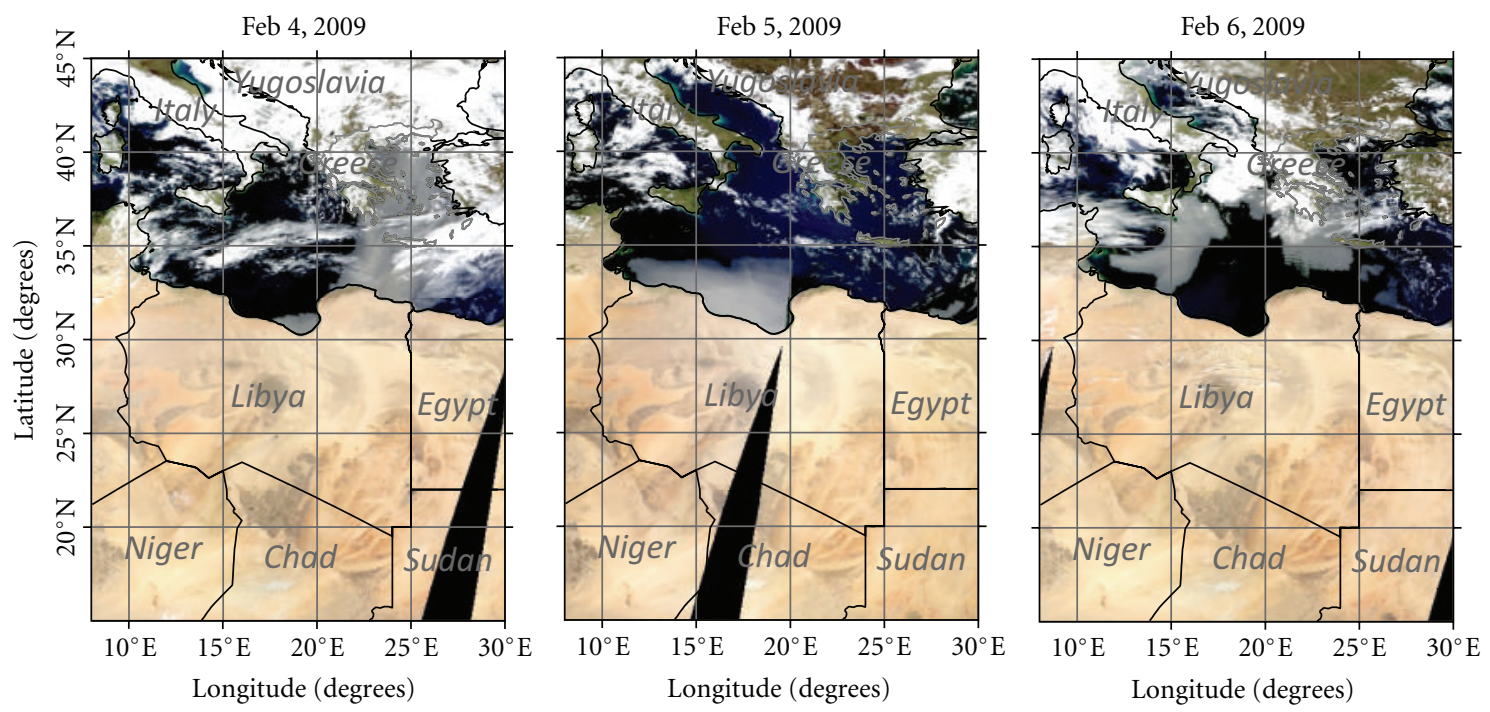

FIGURE 1: Terra-MODIS true color RGB images along the satellite swath over eastern Mediterranean for 4-6 February 2009. Two images are provided for 5 February in order to cover both Libyan desert and eastern Mediterranean.

from combining retrievals of the Dark Target and Deep Blue algorithms of Aqua-MODIS Level 2 data, is shown in Figure 2 for 4-6 February 2009. The white gaps in MODIS observations correspond to lack of data in Level 2 product due to filters such as cloud contamination.

The high $\mathrm{AOD}_{550}$ values (up to 0.9 ) clearly indicate the dust plumes that cover Libya, eastern Mediterranean, and Greece on 4 and 6 February, while they are limited over the Bay of Sirti on 5 February. On 4 February, the thick dust plume (high AOD) originated from the coast of Libya, just east of the coastal city of Benghazi. The area just south of the coastal Libyan mountains constitutes a topographic low and was identified as a significant dust source region [16]. The dust plume is transported northward, being substantially thick in southern to Crete areas, while for northern latitudes it attenuates as being diluted by the removal processes. On 5 February the dust plume is limited without affecting Greece, where clean conditions were prevalent. However, these clean conditions lasted for only one day, since on the next day two intense dust plumes: one from Libya and the other from Tunisia, were joined over Ionian Sea affecting Greece on the 6th and 7th February (not shown). Note also the lower AOD values over Sahara desert as detected only from the Deep Blue algorithm compared to those values given over the sea, mainly attributed to the larger uncertainties in the retrievals over bright surfaces. The lower $\alpha_{550-865}$ values over the oceanic areas affected by dust, although not being so pronounced as the AOD, suggest the presence of coarsemode particles on the dusty days, while they were higher on the clean day ( 5 February), with the low $\alpha_{550-865}$ to be limited in south Mediterranean.

The spatial distribution of OMI-AI is shown in Figure 3 for 4-6 February 2009. The dust plume transported from central to eastern Libya and then over Mediterranean and Greece has a clear signal in AI values (up to 4) on 4 February, in line with the MODIS observations, while on 5 February lower AI values are limited over Libyan desert and coastalAfrican Mediterranean, suggesting the attenuation of the dust event. Desert dust has usually a direct effect on AI because of its strong dependence on the imaginary part of the refractive index in the UV [50] and its transportation at elevated layers into the atmosphere. On the other hand, the two new dust plumes observed over Mediterranean on 6 February (MODIS observations) do not show a strong signal on AI (values below 2.5). It is characteristic that the large AI values are observed more northern than $27^{\circ} \mathrm{N}$ latitude (4 February), while as we will see in the following, the dust source region is detected somewhat southern from that latitude. This fact indicates that in the initial stage of the dust erosion and uplift the AI is rather incapable to allow detection of the event. Dust aerosols transported within the lower boundary layer are easier to be deposited, and their lifetime is much shorter, while in several cases they do not have a clear signal in AI $[25,51]$. For these reasons, one cannot simply use the AI values to compare the relative strengths of dust sources in different climate and meteorological regimes; nevertheless, in certain occasions, the AI can provide a rough measure of relative dust concentrations and, hence, relative source strength $[8,19]$. In interpreting the results, care has to be taken that some surface effects, such as sea glint and ocean color, can also enhance the AI. Furthermore, AI values over some regions have been removed due to swath overlap resulting in large unrealistic values (see [52]). Nevertheless, the advantage of AI is that it can be applied over both land and ocean, thus improving the knowledge about the distribution of dust sources and plumes over the globe $[16,53]$.

3.3. DREAM Simulations. While significant progress has been achieved in characterizing the physical and optical properties as well as the importance of mineral dust in global-scale processes (e.g., $[54,55])$, there has been less 

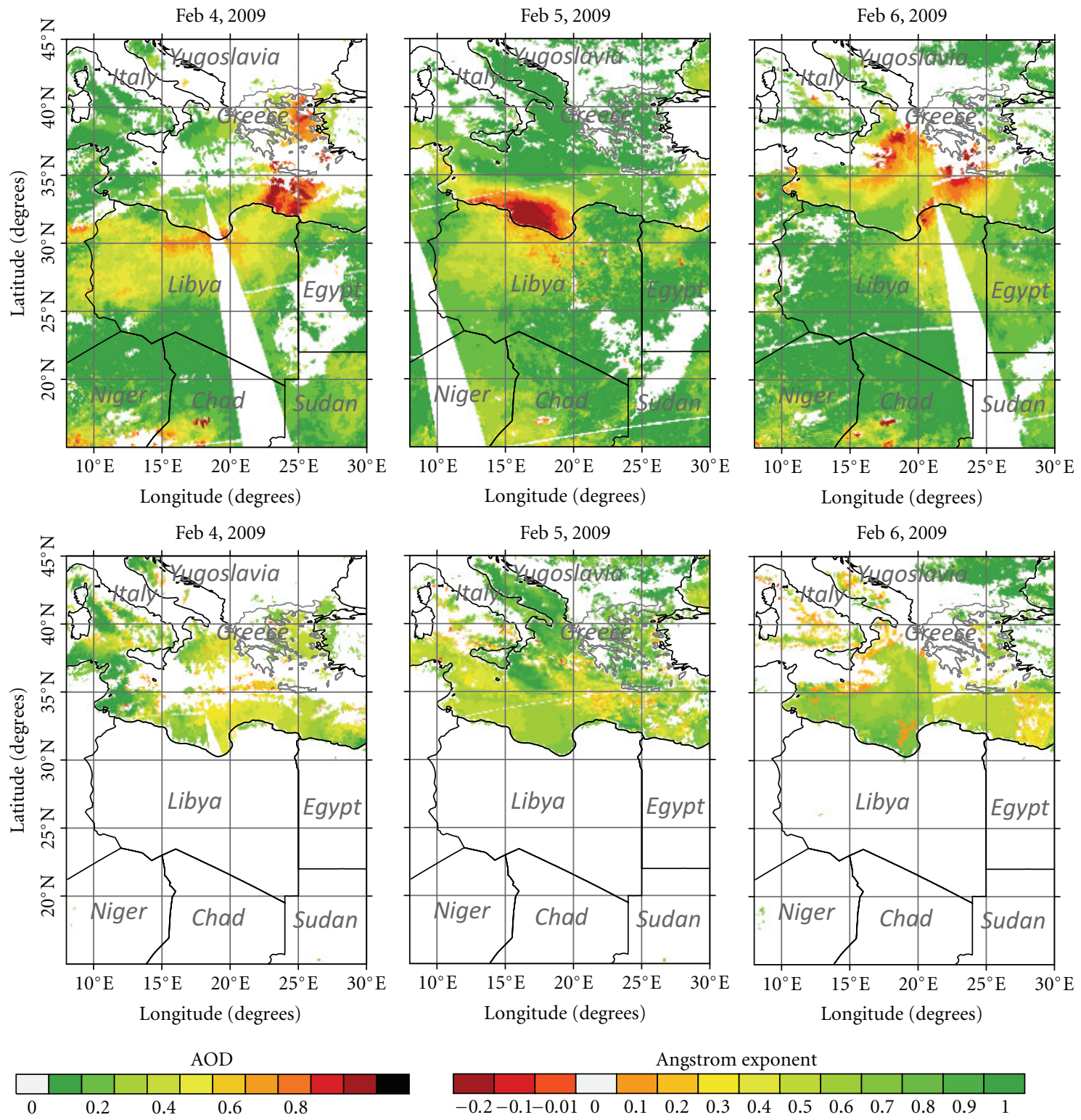

FIGURE 2: Spatial distribution of MODIS-derived Dark Target AOD (over ocean) and Deep Blue AOD (over land) (upper row) and Angstrom exponent over ocean (lower row) according to Level 2 C005.1 Aqua-MODIS retrievals for 4 (left column), 5 (mid-column) and 6 (right column) February 2009 over eastern Mediterranean.

progress in identifying the environmental processes that affect dust generation in the source regions and the meteorological factors that affect the dust transport and deposition [56-58]. Significant contribution to the latter can be provided by the DREAM model, which is under continuous development by comparing the retrievals (spatially and vertically) with ground-based and satellite measurements [47]. The DREAM results regarding the spatial distribution of the dust loading and concentration are presented in Figures 4(a), 4(b), 5(a), and 5(b), for 4 and 6 February, respectively at 18.00 UTC. Regarding the dust loading, the strong southerly winds are responsible for the transport of significant amount of dust from the eastern Libyan coast towards Mediterranean and Greece (Figure 4(a)). The dust storm seems to originate from south Libya around $25^{\circ} \mathrm{N}$ and $15^{\circ} \mathrm{E}$, which is in agreement with MODIS and OMI observations despite the limitations mentioned above. Over the same area, the dust concentration exhibits its maximum values, while high values $\left(>300 \mu \mathrm{g} \mathrm{m}^{-3}\right)$ also observed over most part of Greece (Figure 4(b)), continuously decreasing as the dust plume transported away from Africa. On the same day the maximum PM10 concentrations in Athens reached up to $270 \mu \mathrm{g} \mathrm{m}^{-3}$ comparable to the values predicted by DREAM. The wind field shows that the intense dust storm was driven by the strong southerlies associated with a large trough over Iberian peninsula and northwestern 

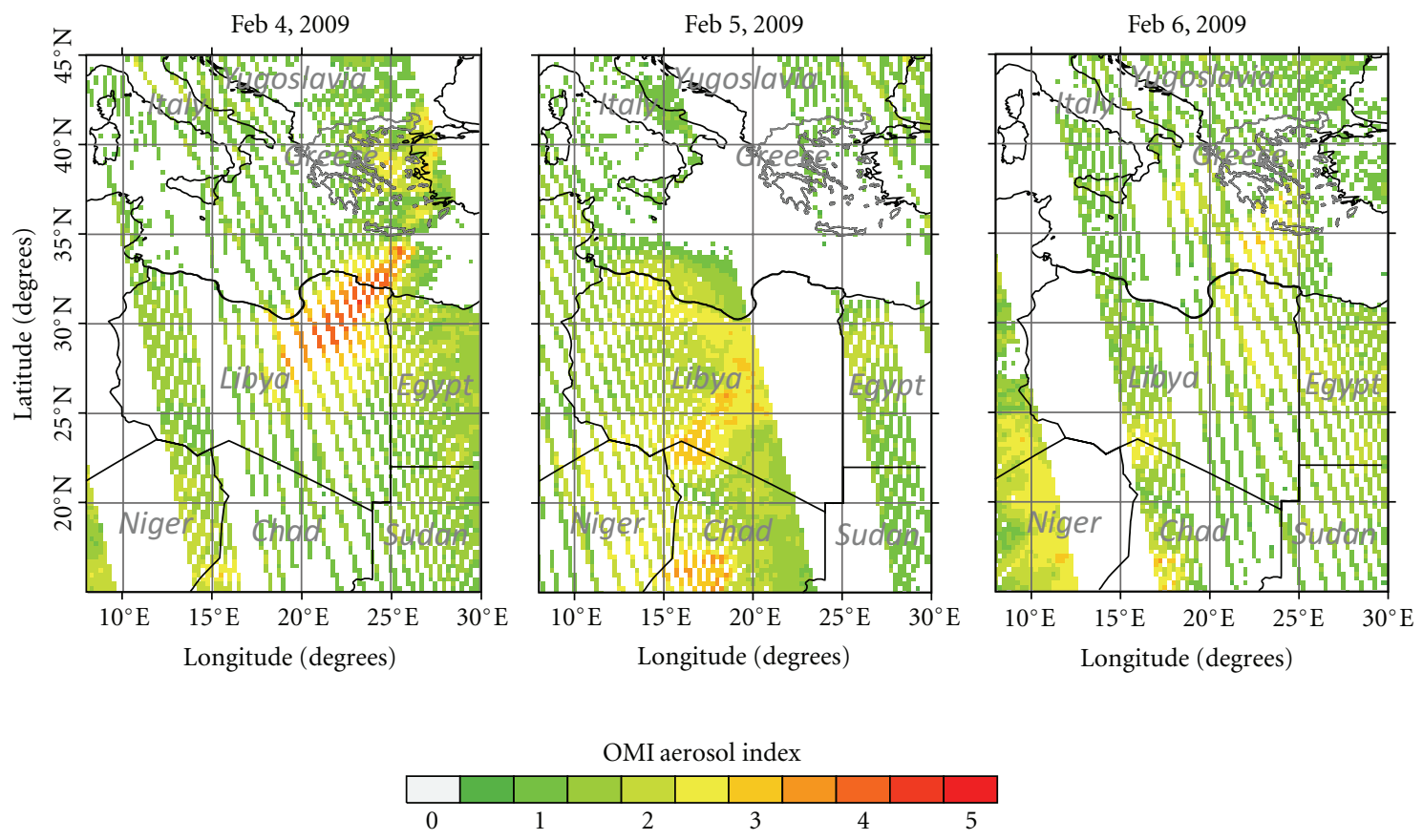

Figure 3: Spatial distribution of OMI-derived aerosol index (AI) over the study region during the period 4-6 February 2009.

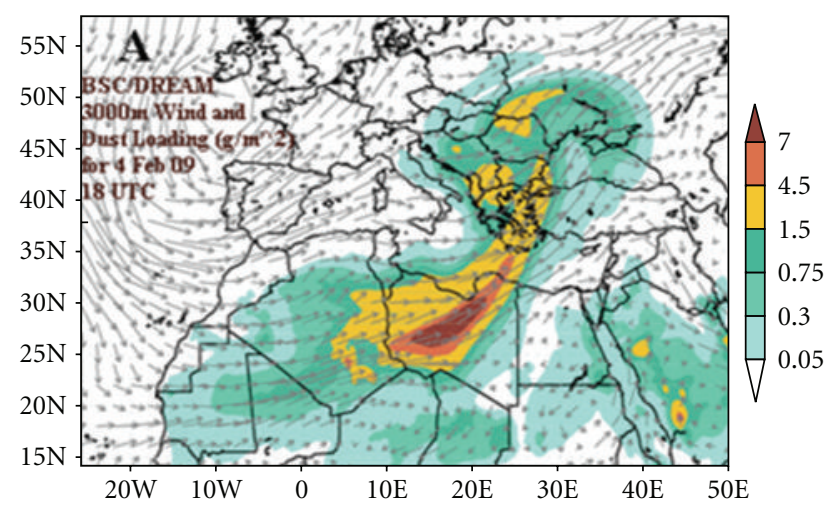

(a)

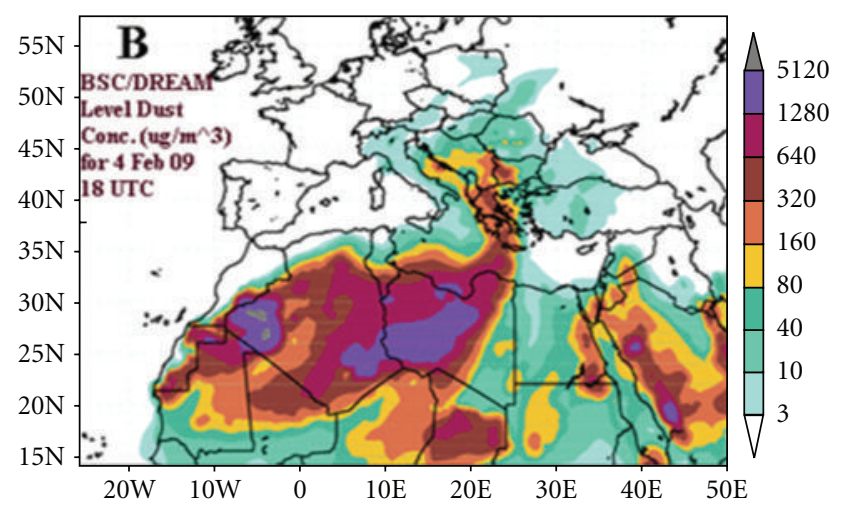

(b)

FIGURE 4: DREAM predictions of dust loading (a) and dust mass concentration (b) on 4 February 2009 for 18:00 UTC.
Africa. Two days later, the same system was also active; however, the presence of an anticyclone over Niger and Chad shifted the trough more to the northwest with a major dust plume originating from Algeria and Tunisia and a minor one from Libya (Figures 5(a) and 5(b)). These two were joined in to one over Ionian Sea affecting Greece on 6, and mainly on 7 February (not shown), as it was transported northeastwards. These simulations are also in line with the satellite observations on the same day.

3.4. Vertical Distribution of Dust. Lidar systems on board satellites have been increasingly available in the recent years for aerosol and dust monitoring since the passive satellite sensors are either incapable to give reliable retrievals over bright surfaces, and/or the presence of clouds causes some gaps in the observations; furthermore, these sensors give data only during daytime. On the other hand, the knowledge of dust-aerosol vertical profiles is very crucial as they influence the radiative forcing, heating rate, and stability of the atmosphere [59, 60]. Thus, CALIPSO observations are used to identify the position of the dust and its vertical distribution along the overpass trajectory. During the studied period (4-6 February 2009), CALIPSO overpasses the area in the nighttime and daytime hours of 5 February (Figures 6 and 7 ). Both figures show the overpass trajectory (moving southwards for nighttime conditions and northwards for daytime) with the vertical profiles of the total attenuated backscatter (TAB) at $532 \mathrm{~nm}$, the attenuated color ratio (ACR) in the 532-1064 nm and the DR. In both figures the presence of clouds is limited over the European continent, so that the dust plume is clearly defined. The hours of the nighttime and daytime overpass (in UTC) are shown below 


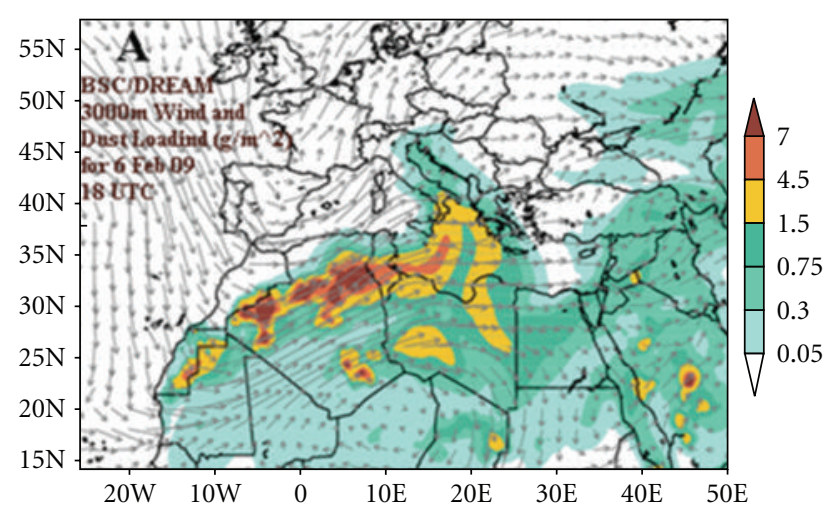

(a)

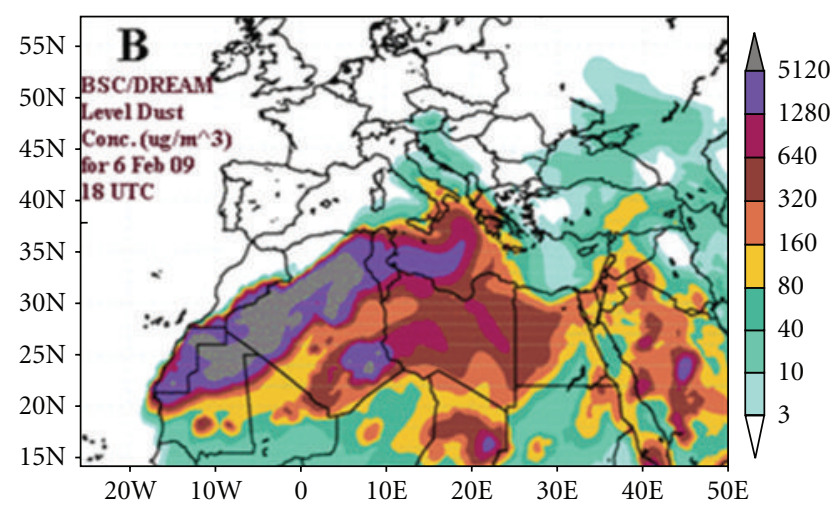

(b)

Figure 5: Same as in Figure 4, but for 6 February 2009 for 18:00 UTC.

the figures (lower $x$-axis) while the information for the coordinates of the overpass (longitude and latitude) is given above the figure (upper $x$-axis).

3.4.1. Nighttime Overpass. The nighttime overpass of CALIPSO over the area of interest lasts about 6-7 min and crosses the western Balkans, Ionian Sea, Mediterranean, and central Libya. The TAB image shows an extended thick (0.004-0.006 $\left.\mathrm{km}^{-} 1 \mathrm{sr}^{-1}\right)$ aerosol layer covering most of the satellite track extending up to $\sim 2.5 \mathrm{~km}$. This aerosol layer originated from the south Libyan Desert $\left(\sim 25^{\circ} \mathrm{N}, 15.5^{\circ} \mathrm{E}\right)$ near to the Chad and Niger borders. All the CALIPSO nighttime profiles are very characteristic regarding the dust source region since for southern latitudes only few aerosols at elevated layers $(3-5 \mathrm{~km})$ are observed. In great consistency, the DREAM simulations highlighted the same area as the dust source region for 4 February (Figure 4 ). Thus, the nighttime CALIPSO overpass is able to detect the uplift of the dust storm, which starts at the morning hours on 4 February as Terra-MODIS observations shown (Figure 1). The northwards pathway of the dust plume on 4 February, which nearly coincided with the CALIPSO overpass, allows CALIPSO to monitor the whole movement of the dust plume. After its exposure the dust plume is gradually increasing in depth reaching up to $2.5 \mathrm{~km}$ in areas $\sim 500 \mathrm{~km}$ away from the dust source (over coastal Libya). As the dust layer crosses Mediterranean, its intensity and thickness are gradually decreasing, while its vertical extend is limited to below $2 \mathrm{~km}$ with a trend of further decreasing. The CALIPSO profiles indicate that the dust plume has a direct effect on the surface aerosol concentrations. Similarly, DREAM showed (not presented) significant dry dust deposition of $\sim 50$ $100 \mu \mathrm{gm}^{-2}$ over Mediterranean and Greece for the afternoon hours on 4 February 2009.

The vertical extent of the present dust outflow is much lower than those observed over Mediterranean during spring, summer, and autumn $[47,61,62]$, where the dust is mainly transported at elevated heights [8]. This may be attributed to the different meteorological conditions prevailing over the area controlling not only the outflow and transport of dust, but also its vertical extend, deposition rates, and lifetime. Thus, in the hot period, the deep mixed layer over Sahara associated with the large convection favors the dust particles to rise up in height, while the absence of intense winds and precipitation favors their longer atmospheric lifetimes and the transport to larger distances. To this respect, studies have found longer duration of dust events over the central and eastern Mediterranean in summer rather than in winter $[25,63]$.

CALIPSO provides also estimation of the backscatterrelated Angstrom exponent between 532 and $1064 \mathrm{~nm}$ named ACR or color index or c-ratio, which is mainly related with the particle size and shape. The ACR can present large differences even for the same aerosol type, since based on that Balis et al. [64] classified the Sahara dust events over Thessaloniki, Greece in three groups with very differing ACR values depending on the intensity of the dust events, the distance from the source region, the deposition of the large particles, the altitude of the dust layer, and mixing with other aerosol types. Ansmann et al. [65] reported that ACR values below 0.5 are associated with large dust particles, comparable to the values presented in the present dust plume.

The lowermost panel of Figure 6 shows the spatiotemporal variation of the DR, which is defined as the ratio of the perpendicular and parallel components of the attenuated backscatter signal [66]. Its values range from about $\sim 0.014$ for a pure molecular atmosphere to $\sim 0.3$, or even more, for the presence of nonspherical particles [67], being a good proxy for spherical and nonspherical aerosol identification. The variations in the DR are due to the detection noise and natural variability of the dust layer. The high values of DR, varying between 0.2 and 0.5 (see Figure $8(\mathrm{a})$ ), indicate the presence of dust with nonspherical particles. Thus, the DR allows inferring the presence of dust over northern Africa and Mediterranean via the large values, which were gradually reduced for northern latitudes due to deposition of the larger dust particles. The observed range of DR and its vertical structure for this specific dust event during February 2009 is consistent with previous values reported over the Sahara region (DR: 0.2 to 0.5) [66]. Similarly, Gobbi et al. [68] quantified the dust impact on air quality in Rome, Italy based on the high DR values during Sahara dust events. Thus, the vertical profiles of TAB, DR, and ACR, derived from CALIOP high-resolution vertical profiling, are highly 


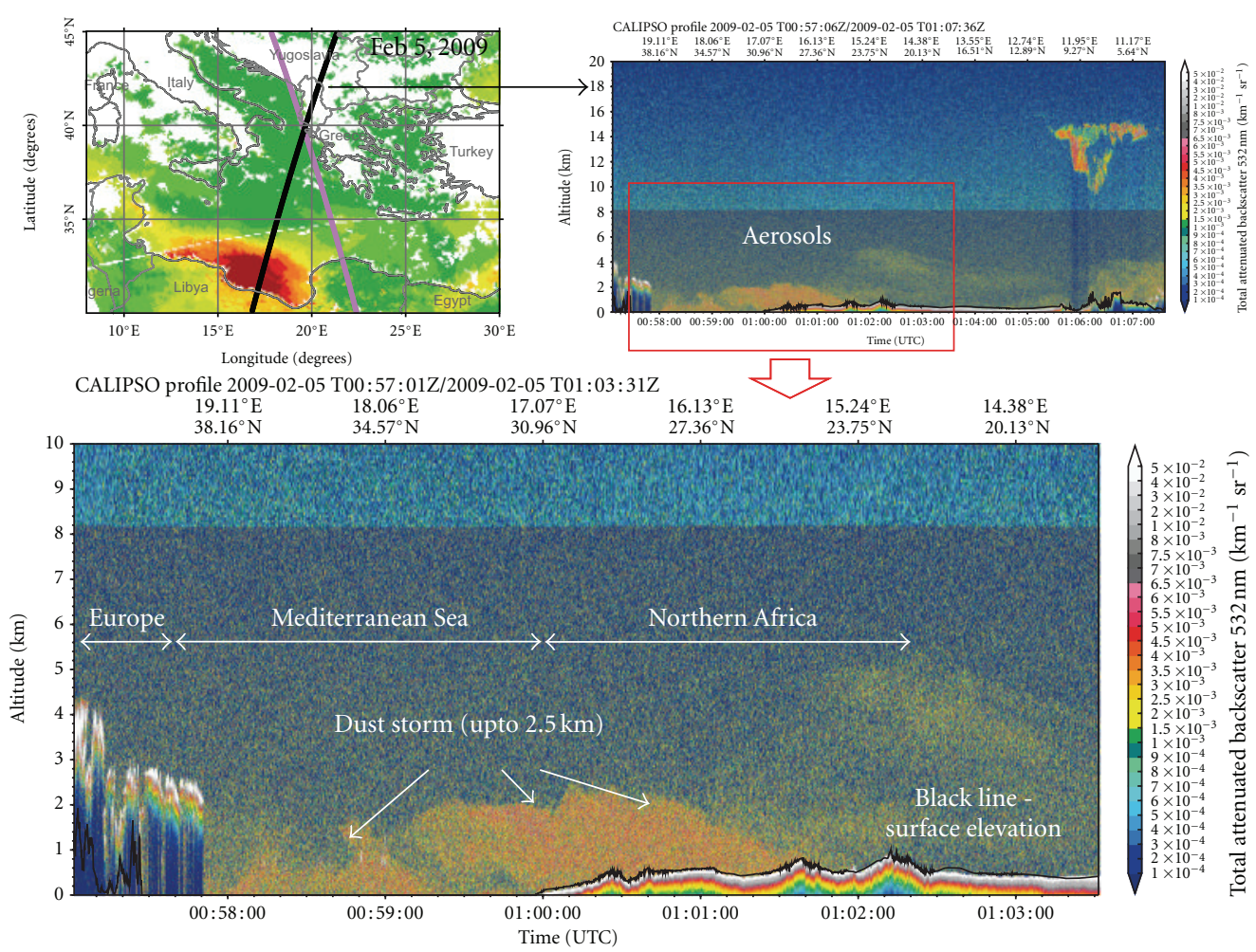

(a) Total attenuated backscatter (TAB at $532 \mathrm{~nm}$ )

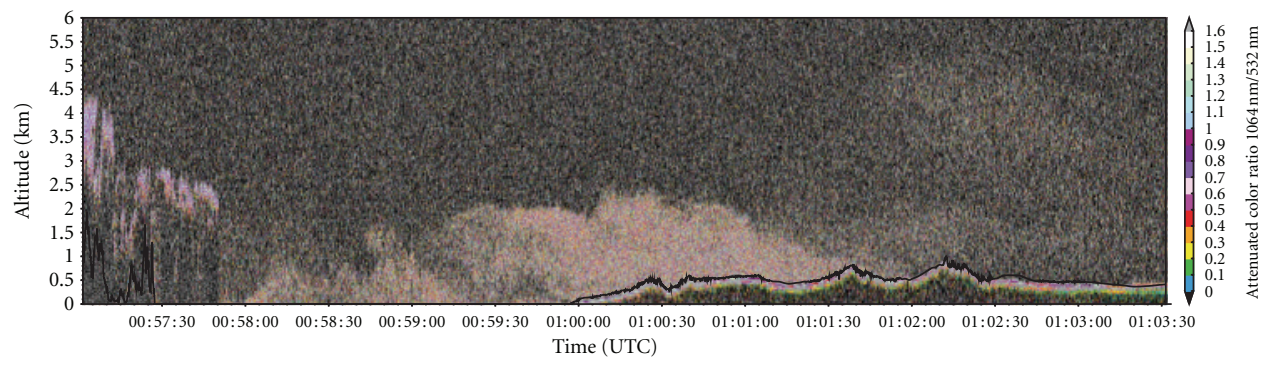

(b) Attenuated color ratio (ACR or c-ratio: 1064/532 nm)
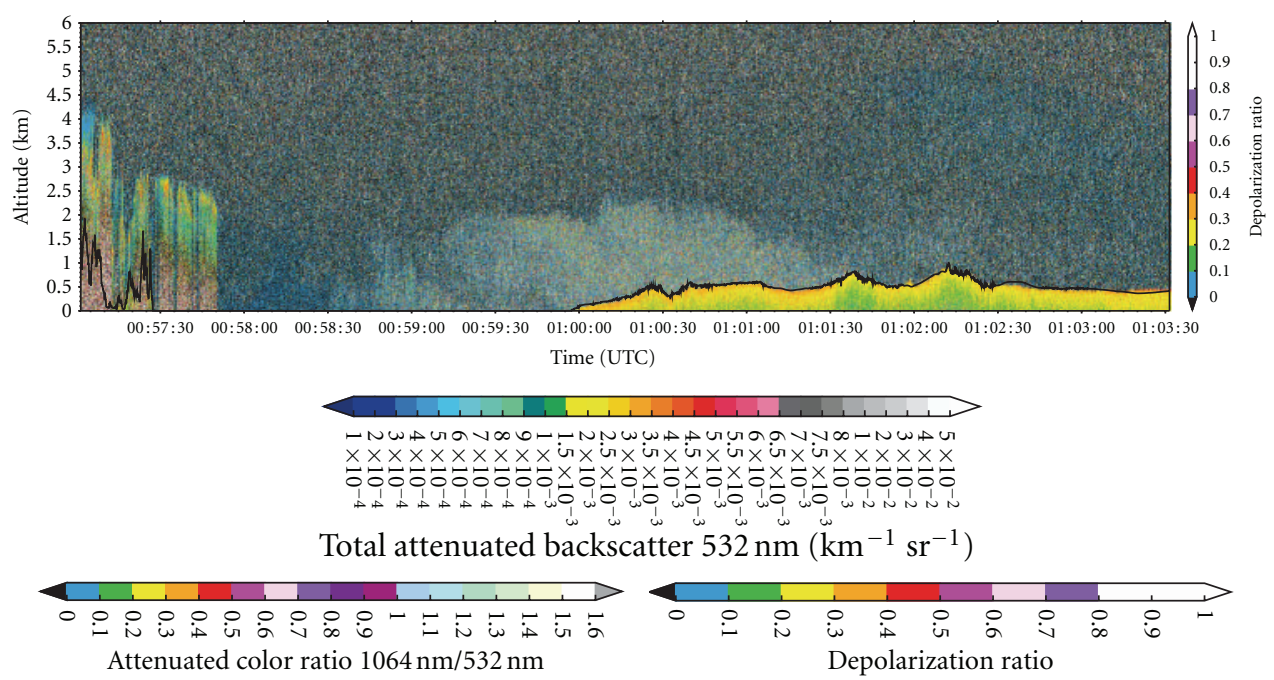

(c) Depolarization ratio (DR or d-ratio) show is its sensitivity towards the vertical measurement $(0-5 \mathrm{~km})$ of desert dust during night

FIgure 6: The vertical profile of the atmosphere using CALIPSO night-time overpass over the Europe-Mediterranean Sea and northern Africa (Sahara desert) showing the presence of dust storm and its vertical extent. The multiple parameters from CALIPSO. 

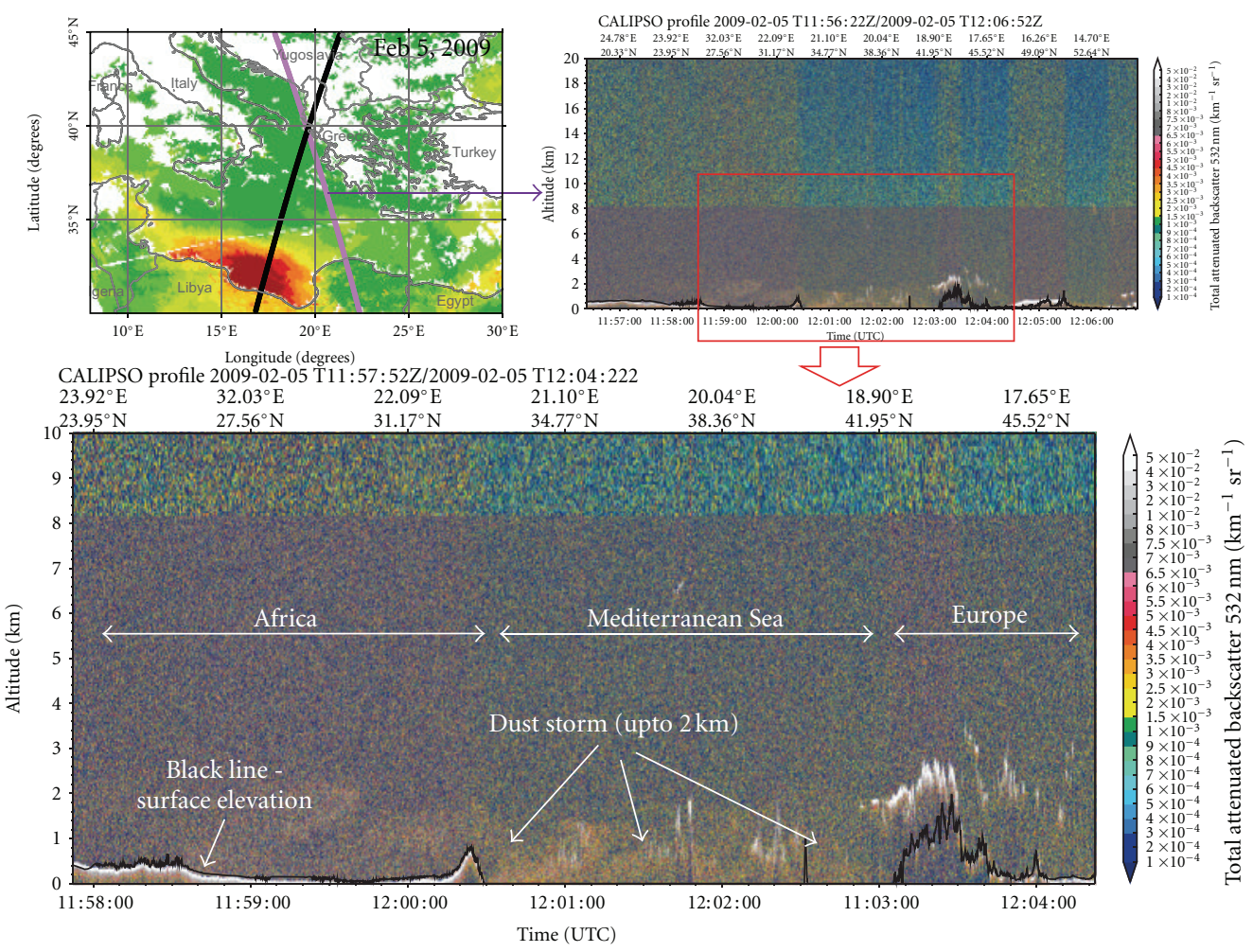

(a) Total attenuated backscatter (TAB at $532 \mathrm{~nm}$ )

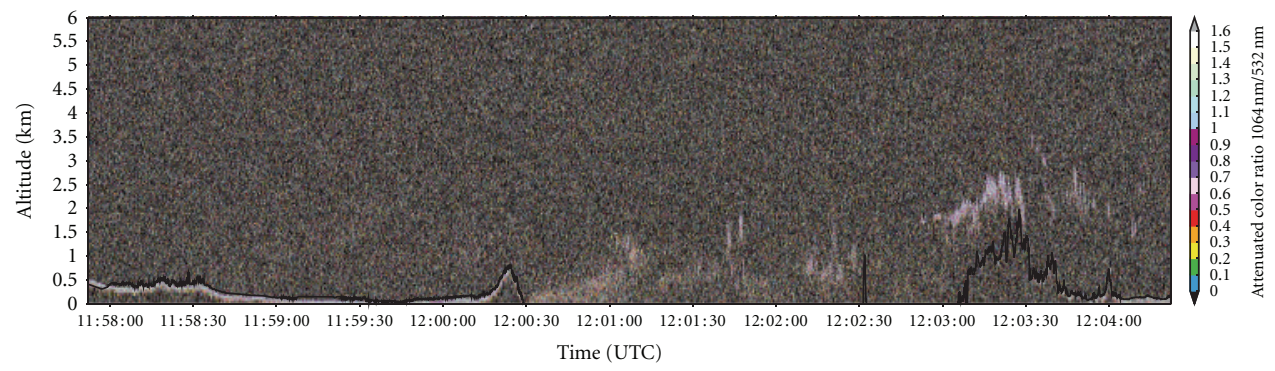

(b) Attenuated color ratio (ACR or c-ratio: 1064/532 nm)
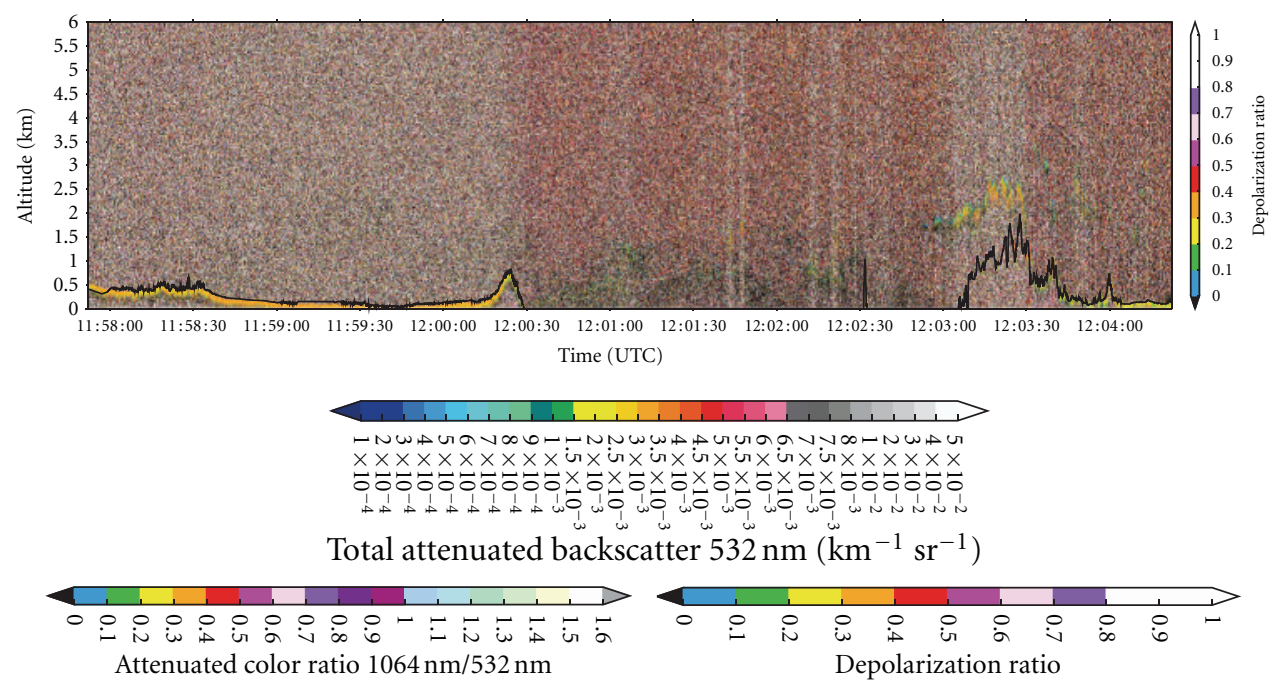

(c) Depolarization ratio (DR or d-ratio) show is its sensitivity towards the vertical measurement $(0-5 \mathrm{~km})$ of desert dust during night

FIgURE 7: Same as in Figure 6, but for the CALIPSO day-time overpass on 5 February. 

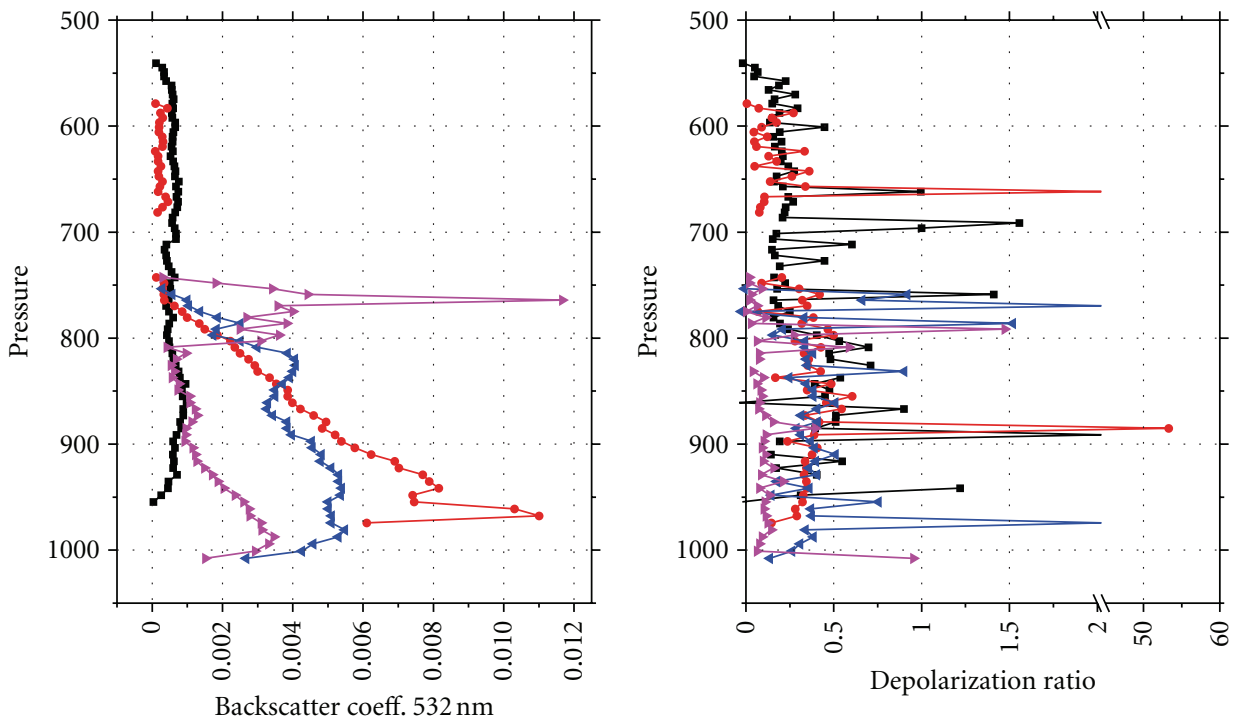

(a)
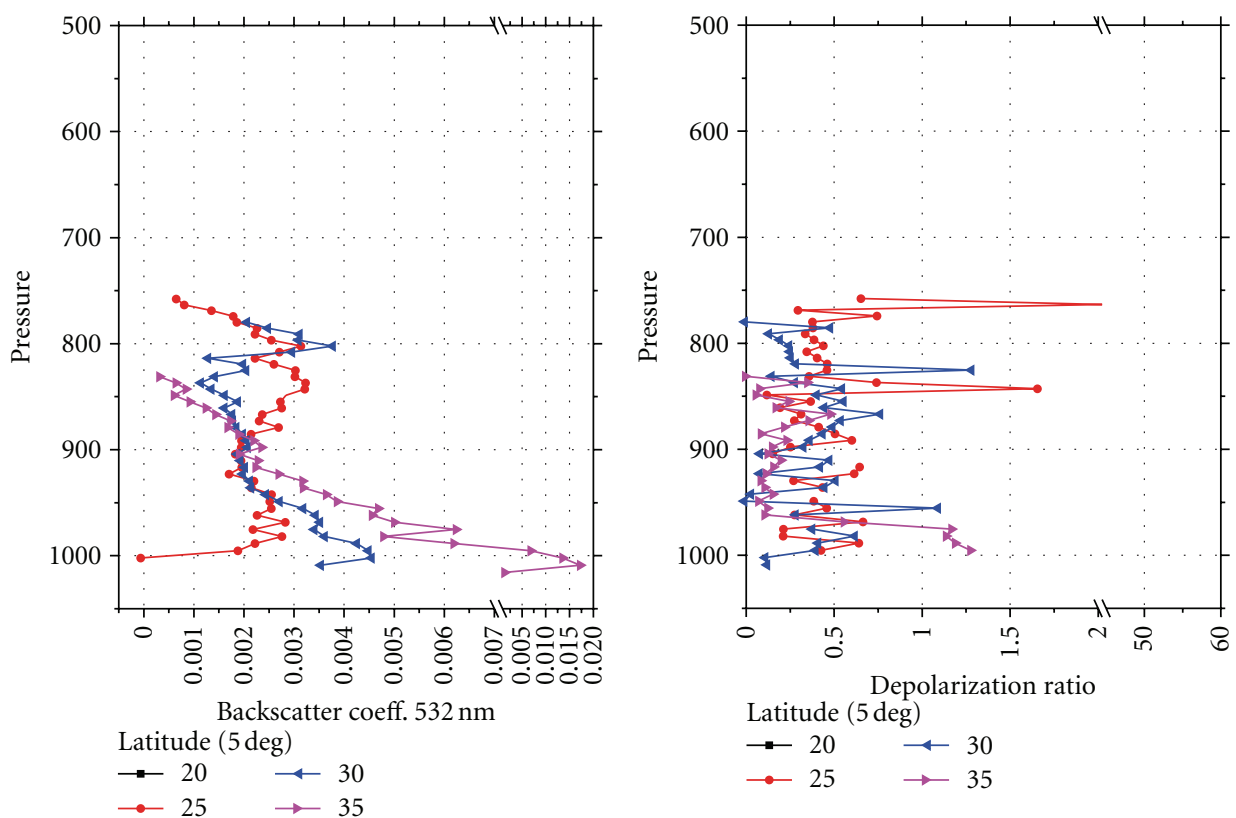

(b)

FIGURE 8: Latitude step-wise variation of CALIPSO measured variables (backscatter coefficient and depolarization ratio) averaged over 5-degree latitude for nighttime (a) and daytime (b) conditions on 5 February 2009.

useful for studying dust, polluted and dust+polluted aerosols $[66,69]$.

3.4.2. Daytime Overpass. The daytime CALIPSO overpass (11:58-12:04 UTC) mainly covers a part of the Ionian Sea, western Libyan Sea and eastern continental Libya, approximately $10^{\circ}$ eastern from the nighttime overpass for latitudes below $25^{\circ} \mathrm{N}$ (Figure 7 ). During the time interval of $\sim 12 \mathrm{hrs}$ between the two CALIPSO overpasses, the dust plume was strongly attenuated over all regions as shown mainly from the TAB image. However, such a conclusion based only on
CALIPSO profiles must be avoided due to different overpass tracks for nighttime and daytime conditions, and, therefore, knowledge about the spatial distribution of aerosols is necessary. This can be justified viewing both overpass tracks and the underlying L2 Aqua-MODIS AOD 500 (upper left corner), which is large along the nighttime CALIPSO overpass (Bay of Sirti) and low along daytime CALIPSO overpass (Eastern Libya). Thus, a comparison between the CALIPSO observations for revealing the dust attenuation during the 12-hrs interval is not applicable over Africa. In contrast, it can be applicable over the Mediterranean, where the difference between the CALIPSO tracks is below 
$5^{\circ}$ in longitude. This comparison clearly reveals that the dust plume is significantly reduced during the daytime hours of 5 February above the Mediterranean and Greece, as MODIS and OMI showed (Figures 2 and 3).

This suggests that the CALIPSO track on 5 February (nighttime conditions) corresponds to the dust plume that affected eastern Mediterranean on 4 February. According to DREAM, this intense dust outbreak started at the morning hours on 4 February; thus, the fact of presence of thick aerosol layers near the source region about 16-hrs later (CALIPSO nighttime overpass) suggests a strong and continuous uplift of dust. On the other hand, the dust plume was being transported northwards very quickly favored by the intense winds, since Terra-MODIS observes it over Mediterranean during the morning hours on 4 February (Figure 1). Due to low signal-to-noise ratio for daytime lidar observations, the parameters related with aerosol size, shape, and type, that is, ACR and DR, are not clearly present.

3.4.3. Aerosol Profiles according to Latitude. The aerosol properties along the dust transport have been found to exhibit a vertical heterogeneity owing to boundary layer dynamics, altitudinal differences in physical and chemical compositions and dilution and gravitational settling of the particles [70]. Thus, the surface-level characteristics may be different compared to the columnar ones as well as to present considerable differences along the dust transport. In this respect, examining the vertical profiles of aerosols for increasing latitudes along the dust plume is of major importance for understanding the settling of dust particles from the upper levels into the boundary layer as well as the altering of dust aerosol properties after mixing with other aerosols into the atmosphere. The vertical profiles of TAB and DR are plotted for different latitudes along the nighttime and daytime CALIPSO overpasses (Figure 8).

During nighttime, the vertical profiles of backscatter coefficient at $532 \mathrm{~nm}$ are strongly dependent on latitude. Near background values are observed for $20^{\circ} \mathrm{N}$, which are dramatically increased at $25^{\circ} \mathrm{N}$, nearby to the dust source region, for altitudes below $750 \mathrm{hPa}(\sim 2.5 \mathrm{~km})$. As the dust plume was transported northward, the surface-level backscatter values decreased and a vertically homogeneous dust layer is observed from the surface to $800 \mathrm{hPa}\left(30^{\circ} \mathrm{N}\right)$, which is further attenuated mainly at elevated heights for northern latitudes. The latter suggests gravitational settling of the dust particles from the upper levels into the lower boundary layer as also observed by Colette et al. [70]. The values of about $0.002-0.003 \mathrm{~km}^{-} 1 \mathrm{sr}^{-1}$ observed at $35^{\circ} \mathrm{N}$ (over south Greece) are comparable to those reported over Lecce, south Italy during dust events [62]. During daytime the vertical profile is much different for $25^{\circ} \mathrm{N}$, with lower values of backscatter due to different CALIPSO overpass track and to attenuation of dust uplift. Also, for $30^{\circ} \mathrm{N}$ the vertical profile exhibits lower values at elevated heights (except a peak at $800 \mathrm{hPa}$ ), while at $35^{\circ} \mathrm{N}$ large backscatter $\left(\sim 0.006 \mathrm{~km}^{-} 1 \mathrm{sr}^{-1}\right)$ is shown near the surface probably indicating mixing of deposited dust with anthropogenic aerosols over Greece.
The vertical profiles of the DR during nighttime exhibit large values $(\sim 0.3-0.5)$ over Africa, without any clear dependence on altitude between surface and $750 \mathrm{hPa}$. Opposite to the backscatter coefficient, DR shows enhanced values also for $20^{\circ} \mathrm{N}$, indicating the presence of dust aerosols even for background conditions over Sahara desert, since DR is independent from the aerosol loading [66]. The much lower DR values $(\sim 0.1)$ at $35^{\circ} \mathrm{N}$ indicate that the concentration of nonspherical dust aerosols was significantly attenuated and the gravitational settling as well as the mixing with anthropogenic aerosols transported from Europe resulted to lower DR. Similarly, Levin et al. [2] found that the dust particles reaching over Israel were coated by sea-salt and sulfate during their crossing over Mediterranean. On the other hand, the DR profiles during daytime are associated with low signal-to-noise ratio exhibiting unreal peaks and gaps; however, the values at $35^{\circ}$ seem to be lower, but near the surface are very large $(>1.0)$, which may be associated with large uncertainties. The combined use of DR and ACR is a proxy for aerosol type identification since Liu et al. [69] reported values for DR and ACR of $\sim 0.17$ (nonsphericity) and 0.8 (coarse particles) for dust occurrence. In the present case, the DR and ACR are higher and lower, respectively, suggesting a thick dust layer.

The overall analysis reveals that CALIPSO profiles may also be used for the dust source identification under certain occasions, in addition to OMI and MODIS data [16, 32]. Furthermore, the synergistic use of these satellite sensors along with MISR multiangle cameras, able to detect aerosols and dust nonsphericity over desert areas [55], and models predicting the whole atmospheric dust cycle, is essential for monitoring of such phenomena. The identification of major dust sources over the globe will enable us to focus on critical regions and to quantify emission rates and inventories in response to environmental conditions. Such knowledge is essential for the improvement of the global dust models in order to assess the effects of climate change on emissions in the future.

\section{Conclusions}

In this paper a synergy of CALIPSO lidar profiles, MODIS and OMI retrievals as well as model DREAM simulations, has been combined to infer the intrusion of Saharan dust over the eastern Mediterranean and Greece during 4-6 February 2009. More specifically, Level 2 Aqua MODIS retrievals for AOD and Angstrom exponent have been used by means of combining Dark Target approach and Deep Blue algorithm (over deserts), in association with L2G OMI-AI values. The CALIPSO data were used to obtain parameters related with aerosol loading, particle size, and shape, that is, attenuated backscatter coefficient at 532, volume depolarization ratio, and attenuated color ratio for nighttime and daytime conditions on 5 February (day and nighttime overpass).

Two intense dust events have been observed over eastern Mediterranean on 4 and 6-7 February 2009, which were well detected by satellites and use of model. CALIPSO and DREAM highlighted the area at $\sim 25^{\circ} \mathrm{N}, 15.5^{\circ} \mathrm{E}$ in the 
Libyan Desert as the dust source for the first event on 4 February, while MODIS and OMI observations justified it. After its exposure the dust was uplifted to $\sim 2.5 \mathrm{~km}$ and moving northwards affecting eastern Mediterranean and Greece. During the transport pathway the intensity of the dust layer decreased significantly, while its vertical extend was limited to boundary layer, below $1-1.5 \mathrm{~km}$, since the dust particles were deposited over the Mediterranean. The CALIPSO profiles revealed that the dust-aerosol loading and properties exhibited considerable variations depending on the distance from the source and the gravitational settling. Synoptically, the results showed that the vertical aerosol profiles derived from CALIPSO can be considered very useful for the detection of the dust plume, its source region, optical and microphysical characteristics, vertical extent, and modification from its genesis and uplift into the atmosphere to the dilution and deposition at the ground.

\section{Acknowledgments}

The MODIS and CALIPSO scientific teams are gratefully acknowledged for providing high quality satellite data via the Langley Research Center Atmospheric Science Data center. The OMI data were obtained via the Giovanni tool, which is also gratefully acknowledged. The DREAM images for the dusty days were obtained from the Barcelona Super-Computing Center, while the AOD data over Crete from the FORTH-CRETE AERONET station, both highly acknowledged. Authors are thankful to Science System and Applications for financial support to us (AKP, MK). They also thank the scientific and technical staff of the National Observatory of Athens and Ministry of Environment in Greece for providing useful meteorological and atmospheric data.

\section{References}

[1] IPCC, "Summary for policymakers," in Climate Change 2007: The Physical Science Basis. Contribution of Working Group I to the Fourth Assessment Report of the Intergovernmental Panel on Climate Change, S. Solomon, D. Qin, M. Manning et al., Eds., Cambridge University Press, New York, NY, USA, 2007.

[2] Z. Levin, E. Ganor, and V. Gladstein, "The effects of desert particles coated with sulfate on rain formation in the eastern Mediterranean," Journal of Applied Meteorology, vol. 35, no. 9, pp. 1511-1523, 1996.

[3] R. Gautam, N. C. Hsu, and K. M. Lau, "Premonsoon aerosol characterization and radiative effects over the Indo-Gangetic plains: implications for regional climate warming," Journal of Geophysical Research D, vol. 115, no. 17, D17208, 2010.

[4] H. El-Askary and M. Kafatos, "Dust storm and black cloud influence on aerosol optical properties over Cairo and the Greater Delta region, Egypt," International Journal of Remote Sensing, vol. 29, no. 24, pp. 7199-7211, 2008.

[5] H. S. Marey, J. C. Gille, H. M. El-Askary, E. A. Shalaby, and M. E. El-Raey, "Study of the formation of the "black cloud" and its dynamics over Cairo, Egypt, using MODIS and MISR sensors," Journal of Geophysical Research D, vol. 115, no. 21, article D21206, 2010.

[6] H. S. Marey, J. C. Gille, H. M. El-Askary, E. A. Shalaby, and M. E. El-Raey, "Aerosol climatology over Nile Delta based on
MODIS, MISR and OMI satellite data," Atmospheric Chemistry and Physics, vol. 11, no. 20, pp. 10637-10648, 2011.

[7] A. K. Prasad, K. H. S. Yang, H. M. El-Askary, and M. Kafatos, "Melting of major Glaciers in the western Himalayas: evidence of climatic changes from long term MSU derived tropospheric temperature trend (1979-2008)," Annales Geophysicae, vol. 27, no. 12, pp. 4505-4519, 2009.

[8] A. K. Prasad, H. El-Askary, and M. Kafatos, "Implications of high altitude desert dust transport from Western Sahara to Nile Delta during biomass burning season," Environmental Pollution, vol. 158, no. 11, pp. 3385-3391, 2010.

[9] A. K. Prasad, H. M. El-Askary, G. A. Asrar, M. Kafatos, and A. Jaswal, "Melting of major glaciers in Himalayas: role of desert dust and anthropogenic aerosols, Planet Earth 2011-Global Warming Challenges and Opportunities for Policy and Practice," E. G. Carayannis, Editor, George Washington University, School of Business, InTech, 2011 http://www.intechopen.com/articles/show/title/melting-of-major-glaciers-inhimalayas-role-of-desert-dust-and-anthropogenic-aerosols.

[10] S. K. Das and A. Jayaraman, "Role of black carbon in aerosol properties and radiative forcing over western India during premonsoon period," Atmospheric Research, vol. 102, no. 3, pp. 320-334, 2011.

[11] I. Tegen, A. A. Lacis, and I. Fung, "The influence on climate forcing of mineral aerosols from disturbed soils," Nature, vol. 380, no. 6573, pp. 419-422, 1996.

[12] A. K. Prasad, S. Singh, S. S. Chauhan, M. K. Srivastava, R. P. Singh, and R. Singh, "Aerosol radiative forcing over the Indo-Gangetic plains during major dust storms," Atmospheric Environment, vol. 41, no. 29, pp. 6289-6301, 2007.

[13] T. Claquin, M. Schulz, Y. Balkanski, and O. Boucher, "Uncertainties in assessing radiative forcing by mineral dust," Tellus, Series B, vol. 50, no. 5, pp. 491-505, 1998.

[14] F. Patadia, E. S. Yang, and S. A. Christopher, "Does dust change the clear sky top of atmosphere shortwave flux over high surface reflectance regions?" Geophysical Research Letters, vol. 36, no. 15, article L15825, 2009.

[15] S. Kinne and R. Pueschel, "Aerosol radiative forcing for Asian continental outflow," Atmospheric Environment, vol. 35, no. 30, pp. 5019-5028, 2001.

[16] J. M. Prospero, P. Ginoux, O. Torres, S. E. Nicholson, and T. E. Gill, "Environmental characterization of global sources of atmospheric soil dust identified with the Nimbus 7 Total Ozone Mapping Spectrometer (TOMS) absorbing aerosol product," Reviews of Geophysics, vol. 40, no. 1, 2002.

[17] H. M. El-Askary, S. Sarkar, M. Kafatos, and T. A. El-Ghazawi, "A multisensor approach to dust storm monitoring over the nile delta," IEEE Transactions on Geoscience and Remote Sensing, vol. 41, no. 10, pp. 2386-2391, 2003.

[18] N. J. Middleton and A. S. Goudie, "Saharan dust: sources and trajectories," Transactions of the Institute of British Geographers, vol. 26, no. 2, pp. 165-181, 2001.

[19] S. Engelstaedter, I. Tegen, and R. Washington, "North African dust emissions and transport," Earth-Science Reviews, vol. 79, no. 1-2, pp. 73-100, 2006.

[20] A. K. Prasad and R. P. Singh, "Changes in aerosol parameters during major dust storm events (2001-2005) over the IndoGangetic Plains using AERONET and MODIS data," Journal of Geophysical Research D, vol. 112, no. 9, article D09208, 2007.

[21] F. Barnaba and G. P. Gobbi, "Aerosol seasonal variability over the Mediterranean region and relative impact of maritime, continental and Saharan dust particles over the basin from MODIS data in the year 2001," Atmospheric Chemistry and Physics, vol. 4, no. 9-10, pp. 2367-2391, 2004. 
[22] D. Antoine and D. Nobileau, "Recent increase of Saharan dust transport over the Mediterranean Sea, as revealed from ocean color satellite (SeaWiFS) observations," Journal of Geophysical Research D, vol. 111, no. 12, article D12214, 2006.

[23] H. El-Askary, R. Farouk, C. Ichoku, and M. Kafatos, "Transport of dust and anthropogenic aerosols across Alexandria, Egypt," Annales Geophysicae, vol. 27, no. 7, pp. 2869-2879, 2009.

[24] D. G. Kaskaoutis, P. T. Nastos, P. G. Kosmopoulos, and H. D. Kambezidis, "The combined use of satellite data, air-mass trajectories and model applications for monitoring of the dust transport over Athens, Greece," International Journal of Remote Sensing, vol. 31, pp. 5089-5109, 2010.

[25] D. G. Kaskaoutis, P. G. Kosmopoulos, P. T. Nastos, H. D. Kambezidis, M. Sharma, and W. Mehdi, “Transport pathways of Sahara dust over Athens, Greece as detected by MODIS and TOMS," Geomatics, Natural Hazards and Risk, vol. 3, no. 1, pp. 35-54, 2012.

[26] A. K. Prasad, R. P. Singh, and A. Singh, "Seasonal climatology of aerosol optical depth over the Indian subcontinent: trend and departures in recent years," International Journal of Remote Sensing, vol. 27, no. 12, pp. 2323-2329, 2006.

[27] A. K. Prasad and R. P. Singh, "Comparison of MISR-MODIS aerosol optical depth over the Indo-Gangetic basin during the winter and summer seasons (2000-2005)," Remote Sensing of Environment, vol. 107, no. 1-2, pp. 109-119, 2007.

[28] J. L. Guerrero-Rascado, F. J. Olmo, I. Avilés-Rodríguez et al., "Extreme saharan dust event over the southern iberian peninsula in september 2007: active and passive remote sensing from surface and satellite," Atmospheric Chemistry and Physics, vol. 9, no. 21, pp. 8453-8469, 2009.

[29] K. V. S. Badarinath, S. K. Kharol, D. G. Kaskaoutis, A. R. Sharma, V. Ramaswamy, and H. D. Kambezidis, "Long-range transport of dust aerosols over the Arabian Sea and Indian region-A case study using satellite data and ground-based measurements," Global and Planetary Change, vol. 72, no. 3, pp. 164-181, 2010.

[30] R. C. Levy, L. A. Remer, D. Tanré et al., "Evaluation of the moderate-resolution imaging spectroradiometer (MODIS) retrievals of dust aerosol over the ocean during PRIDE," Journal of Geophysical Research D, vol. 108, article 8594, no. 19, 13 pages, 2003.

[31] D. G. Kaskaoutis, H. D. Kambezidis, P. T. Nastos, and P. G. Kosmopoulos, "Study on an intense dust storm over Greece," Atmospheric Environment, vol. 42, no. 29, pp. 6884-6896, 2008.

[32] M. C. Baddock, J. E. Bullard, and R. G. Bryant, "Dust source identification using MODIS: a comparison of techniques applied to the Lake Eyre Basin, Australia," Remote Sensing of Environment, vol. 113, no. 7, pp. 1511-1528, 2009.

[33] N. C. Hsu, S. C. Tsay, M. D. King, and J. R. Herman, "Deep Blue retrievals of Asian aerosol properties during ACE-Asia," IEEE Transactions on Geoscience and Remote Sensing, vol. 44, no. 11, Article ID 1717707, pp. 3180-3195, 2006.

[34] S. Generoso, I. Bey, M. Labonne, and F.-M. Bréon, "Aerosol vertical distribution in dust outflow over the Atlantic: comparisons between GEOS-Chem and Cloud-Aerosol Lidar and Infrared Pathfinder Satellite Observation (CALIPSO)," Journal of Geophysical Research D, vol. 113, no. 24, article D24209, 2008.

[35] S. H. Wang, N. H. Lin, M. D. Chou et al., "Profiling transboundary aerosols over Taiwan and assessing their radiative effects," Journal of Geophysical Research D, vol. 115, no. 23, article D00K31, 2010.
[36] K. V. S. Badarinath, S. Kumar Kharol, D. G. Kaskaoutis, and H. D. Kambezidis, "Dust storm over Indian region and its impact on the ground reaching solar radiation-a case study using multi-satellite data and ground measurements," Science of the Total Environment, vol. 384, pp. 316-332, 2007.

[37] R. C. Levy, L. A. Remer, and O. Dubovik, "Global aerosol optical properties and application to Moderate Resolution Imaging Spectroradiometer aerosol retrieval over land," Journal of Geophysical Research D, vol. 112, no. 13, article D13210, 2007.

[38] J. Huang, P. Minnis, Y. Yi et al., "Summer dust aerosols detected from CALIPSO over the Tibetan Plateau," Geophysical Research Letters, vol. 34, no. 18, article L18805, 2007.

[39] R. Gautam, Z. Liu, R. P. Singh, and N. C. Hsu, "Two contrasting dust-dominant periods over India observed from MODIS and CALIPSO data," Geophysical Research Letters, vol. 36, no. 6, article L06813, 2009.

[40] B. Chen, J. Huang, P. Minnis et al., "Detection of dust aerosol by combining CALIPSO active lidar and passive IIR measurements," Atmospheric Chemistry and Physics, vol. 10, no. 9, pp. 4241-4251, 2010.

[41] R. R. Rogers, C. A. Hostetler, J. W. Hair et al., "Assessment of the CALIPSO Lidar $532 \mathrm{~nm}$ attenuated backscatter calibration using the NASA LaRC airborne high spectral resolution lidar," Atmospheric Chemistry and Physics Discussions, vol. 10, no. 11, pp. 28355-28398, 2010.

[42] R. L. Curier, J. P. Veefkind, R. Braak, B. Veihelmann, O. Torres, and G. de Leeuw, "Retrieval of aerosol optical properties from OMI radiances using a multiwavelength algorithm: application to western Europe," Journal of Geophysical Research $D$, vol. 113, no. 17, article D17S90, 2008.

[43] P. F. Levelt, G. H. J. Van Den Oord, M. R. Dobber et al., "The ozone monitoring instrument," IEEE Transactions on Geoscience and Remote Sensing, vol. 44, no. 5, pp. 1093-1100, 2006.

[44] N. C. Hsu, J. R. Herman, O. Torres et al., "Comparisons of the TOMS aerosol index with Sun-photometer aerosol optical thickness: results and applications," Journal of Geophysical Research D, vol. 104, no. 6, pp. 6269-6279, 1999.

[45] S. Nickovic, G. Kallos, A. Papadopoulos, and O. Kakaliagou, "A model for prediction of desert dust cycle in the atmosphere," Journal of Geophysical Research D, vol. 106, no. 16, pp. 1811318129, 2001.

[46] C. Pérez, S. Nickovic, J. M. Baldasano, M. Sicard, F. Rocadenbosch, and V. E. Cachorro, "A long Saharan dust event over the western Mediterranean: lidar, Sun photometer observations, and regional dust modeling," Journal of Geophysical Research $D$, vol. 111, no. 15, article D15214, 2006.

[47] V. Amiridis, M. Kafatos, C. Perez et al., "The potential of the synergistic use of passive and active remote sensing measurements for the validation of a regional dust model," Annales Geophysicae, vol. 27, no. 8, pp. 3155-3164, 2009.

[48] D. Meloni, A. di Sarra, F. Monteleone, G. Pace, S. Piacentino, and D. M. Sferlazzo, "Seasonal transport patterns of intense Saharan dust events at the Mediterranean island of Lampedusa," Atmospheric Research, vol. 88, no. 2, pp. 134-148, 2008.

[49] N. G. Prezerakos, A. G. Paliatsos, and K. V. Koukouletsos, "Diagnosis of the relationship between dust storms over the Sahara desert and dust deposit or coloured rain in the South Balkans," Advances in Meteorology, vol. 2010, Article ID 760546, 14 pages, 2010.

[50] M. de Graaf, P. Stammes, O. Torres, and R. B. A. Koelemeijer, "Absorbing Aerosol Index: sensitivity analysis, application to 
GOME and comparison with TOMS," Journal of Geophysical Research D, vol. 110, no. 1, article D01201, 2005.

[51] O. Torres, P. K. Bhartia, J. R. Herman, A. Sinyuk, P. Ginoux, and B. Holben, "A long-term record of aerosol optical depth from TOMS observations and comparison to AERONET measurements," Journal of the Atmospheric Sciences, vol. 59, no. 3, pp. 398-413, 2002.

[52] D. G. Kaskaoutis, P. T. Nastos, P. G. Kosmopoulos, H. D. Kambezidis, S. K. Kharol, and K. V. S. Badarinath, "The AuraOMI Aerosol Index distribution over Greece," Atmospheric Research, vol. 98, no. 1, pp. 28-39, 2010.

[53] P. Alpert, P. Kishcha, A. Shtivelman, S. O. Krichak, and J. H. Joseph, "Vertical distribution of Saharan dust based on 2.5year model predictions," Atmospheric Research, vol. 70, no. 2, pp. 109-130, 2004.

[54] O. V. Kalashnikova, R. Kahn, I. N. Sokolik, and W. H. Li, "Ability of multiangle remote sensing observations to identify and distinguish mineral dust types: optical models and retrievals of optically thick plumes," Journal of Geophysical Research D, vol. 110, no. 18, article D18S14, 2005.

[55] R. Kahn, A. Petzold, M. Wendisch et al., "Desert dust aerosol air mass mapping in the western Sahara, using particle properties derived from space-based multi-angle imaging," Tellus, Series B, vol. 61, no. 1, pp. 239-251, 2009.

[56] M. Liu, D. L. Westphal, S. Wang et al., "A high-resolution numerical study of the Asian dust storms of April 2001," Journal of Geophysical Research D, vol. 108, no. 23, article 8653, 2003.

[57] I. Tegen, M. Werner, S. P. Harrison, and K. E. Kohfeld, "Relative Importance of climate and land use in determining present and future global soil dust emission," Geophysical Research Letters, vol. 31, article L05105, 2004.

[58] Y. H. Lee, K. Chen, and P. J. Adams, "Development of a global model of mineral dust aerosol microphysics," Atmospheric Chemistry and Physics, vol. 9, no. 7, pp. 2441-2458, 2009.

[59] H. Guan, B. Schmid, A. Bucholtz, and R. Bergstrom, "Sensitivity of shortwave radiative flux density, forcing, and heating rate to the aerosol vertical profile," Journal of Geophysical Research, vol. 115, D06209, 2010.

[60] C. Lemaître, C. Flamant, J. Cuesta et al., "Radiative heating rates profiles associated with a springtime case of Bodélé and Sudan dust transport over West Africa," Atmospheric Chemistry and Physics, vol. 10, no. 17, pp. 8131-8150, 2010.

[61] G. P. Gobbi, F. Barnaba, R. Giorgi, and A. Santacasa, "Altitude-resolved properties of a Saharan dust event over the Mediterranean," Atmospheric Environment, vol. 34, no. 29-30, pp. 5119-5127, 2000.

[62] G. Pavese, F. De Tomasi, M. Calvello, F. Esposito, and M. R. Perrone, "Detection of Sahara dust intrusions during mixed advection patterns over south-east Italy: a case study," Atmospheric Research, vol. 92, no. 4, pp. 489-504, 2009.

[63] D. Meloni, A. di Sarra, G. Biavati et al., "Seasonal behavior of Saharan dust events at the Mediterranean island of Lampedusa in the period 1999-2005," Atmospheric Environment, vol. 41, no. 14, pp. 3041-3056, 2007.

[64] D. S. Balis, V. Amiridis, S. Nickovic, A. Papayannis, and C. Zerefos, "Optical properties of Saharan dust layers as detected by a Raman lidar at Thessaloniki, Greece," Geophysical Research Letters, vol. 31, no. 13, article L13104, 2004.

[65] A. Ansmann, J. Bösenberg, A. Chiakovsky et al., "Long-range transport of Saharan dust to northern Europe. The 11-16 October 2001 outbreak observed with EARLINET," Journal of Geophysical Research D, vol. 108, no. 24, article 4783, 2003.
[66] D. Liu, Z. Wang, Z. Liu, D. Winker, and C. Trepte, "A height resolved global view of dust aerosols from the first year CALIPSO lidar measurements," Journal of Geophysical Research D, vol. 113, no. 16, article D16214, 2008.

[67] A. M. Tafuro, F. Barnaba, F. De Tomasi, M. R. Perrone, and G. P. Gobbi, "Saharan dust particle properties over the central Mediterranean," Atmospheric Research, vol. 81, no. 1, pp. 6793, 2006.

[68] G. P. Gobbi, F. Barnaba, and L. Ammannato, "Estimating the impact of Saharan dust on the year 2001 PM10 record of Rome, Italy," Atmospheric Environment, vol. 41, no. 2, pp. 261275, 2007.

[69] Z. Liu, D. Liu, J. Huang et al., "Airborne dust distributions over the Tibetan Plateau and surrounding areas derived from the first year of CALIPSO lidar observations," Atmospheric Chemistry and Physics, vol. 8, no. 16, pp. 5045-5060, 2008.

[70] A. Colette, L. Menut, M. Haeffelin, and Y. Morille, "Impact of the transport of aerosols from the free troposphere towards the boundary layer on the air quality in the Paris area," Atmospheric Environment, vol. 42, no. 2, pp. 390-402, 2008. 

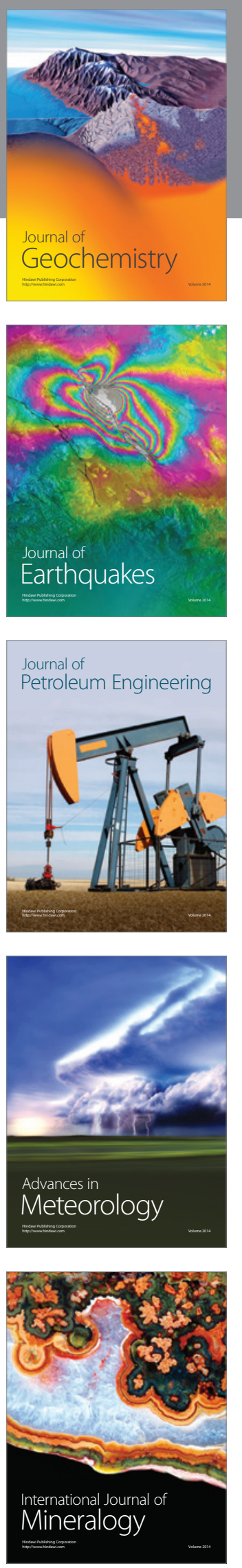
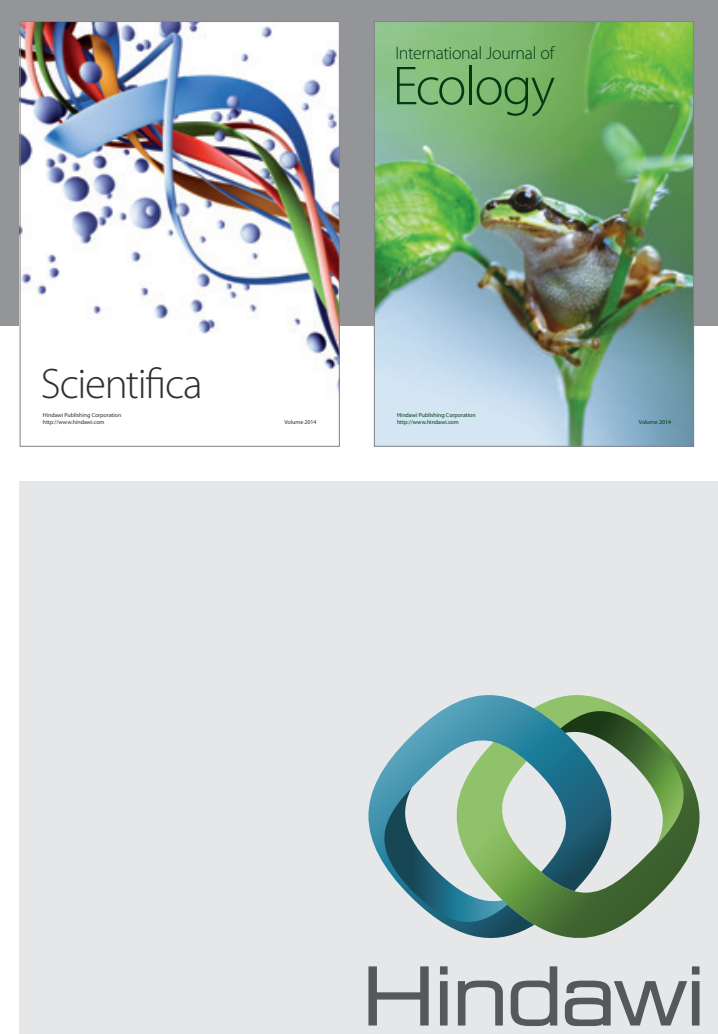

Submit your manuscripts at http://www.hindawi.com
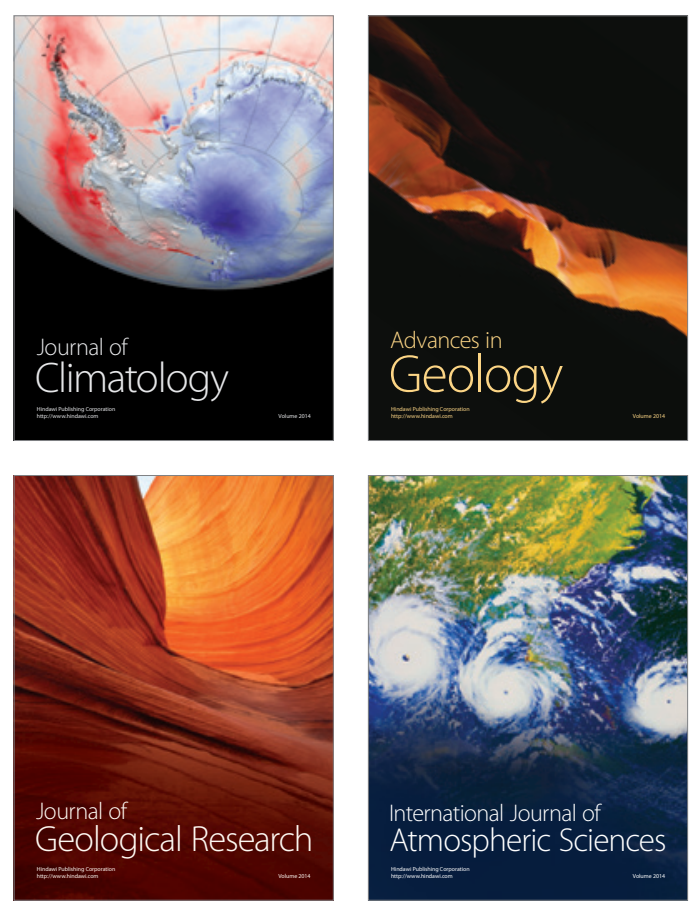
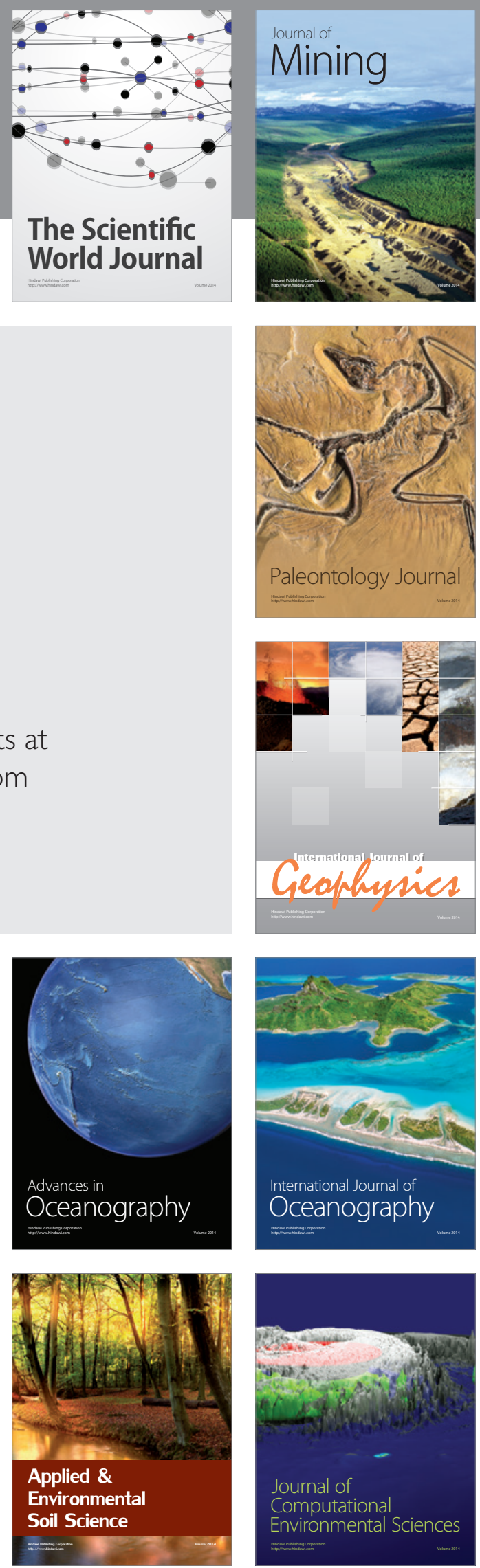